\title{
Functional decorations: post-translational modifications and heart disease delineated by targeted proteomics
}

\author{
Kiersten A Liddy', Melanie Y White, ${ }^{1,2}$ and Stuart J Cordwell1,2*
}

\begin{abstract}
The more than 300 currently identified posttranslational modifications (PTMs) provides great scope for subtle or dramatic alteration of protein structure and function. Furthermore, the rapid and transient nature of many PTMs allows efficient signal transmission in response to internal and environmental stimuli. PTMs are predominantly added by enzymes, and the enzymes responsible (such as kinases) are thus attractive targets for therapeutic interventions. Modifications can be grouped according to their stability or transience (reversible versus irreversible): irreversible types (such as irreversible redox modifications or protein deamidation) are often associated with aging or tissue injury, whereas transient modifications are associated with signal propagation and regulation. This is particularly important in the setting of heart disease, which comprises a diverse range of acute (such as ischemia/reperfusion), chronic (such as heart failure, dilated cardiomyopathy) and genetic (such as hypertrophic cardiomyopathy) disease states, all of which have been associated with protein PTM. Recently the interplay between diverse PTMs has been suggested to also influence cellular function, with cooperation or competition for sites of modification possible. Here we discuss the utility of proteomics for examining PTMs in the context of the molecular mechanisms of heart disease.
\end{abstract}

\section{Heart disease and post-translational modifications} Cardiovascular disease is the leading cause of morbidity and mortality in the developed world. It encompasses

\footnotetext{
*Correspondence: stuart.cordwell@sydney.edu.au

'School of Molecular Bioscience, The University of Sydney, 2006 Sydney, Australia 2Discipline of Pathology, School of Medical Sciences, The University of Sydney, 2006 Sydney, Australia
}

various acute and chronic etiologies, including vascular disease (such as atherosclerosis) and heart disease (including hypertension, ischemic heart disease, heart failure and the cardiomyopathies). Cardiac proteins are continuously synthesized and degraded to ensure proteome homeostasis and to generate necessary functions for satisfying the systemic demand for oxygenated blood. The state of the myocardium, which is predominantly made up of cardiomyocytes, dictates the balance between the synthesis and turnover of proteins that ensures that biochemical demands are met. An additional level of regulation involves signal sequences within proteins that mediate folding, trafficking to subcellular destinations and the formation of protein complexes. A still higherorder level of regulation consists of chemical and physical PTMs, and influences the physiological aspects of function and determines the half-life of proteins and their interactions with other proteins, ligands and DNA (Figure 1).

PTMs act as a mechanism for precise tuning of the function(s) of proteins, typically by inducing conformational changes that subtly or dramatically alter the overall tertiary structure. Modifications vary in their ability to alter protein function; for enzymes, a PTM can either trigger or repress activity, meaning that function can be controlled without the need to synthesize new protein or degrade the existing pool. Such activity must be energetically favorable for the cell. PTMs can be broadly classed into three groups: enzymatic, in which the addition and subtraction of the modification is regulated by proteins; chemical, in which the modification is induced by changes in the local environment, such as cellular $\mathrm{pH}$; and, less commonly, physical, in which proteins are targeted for cleavage or degradation, for example matrix metalloproteinases in extracellular matrix remodeling after myocardial infarction. It is estimated that $5 \%$ or more of the human proteome comprises proteins involved in enzymatic PTM [1]. These include kinases, glycosyltransferases, acetyltransferases and others that add specific moieties to proteins, and their counterparts, such as phosphatases that remove these 


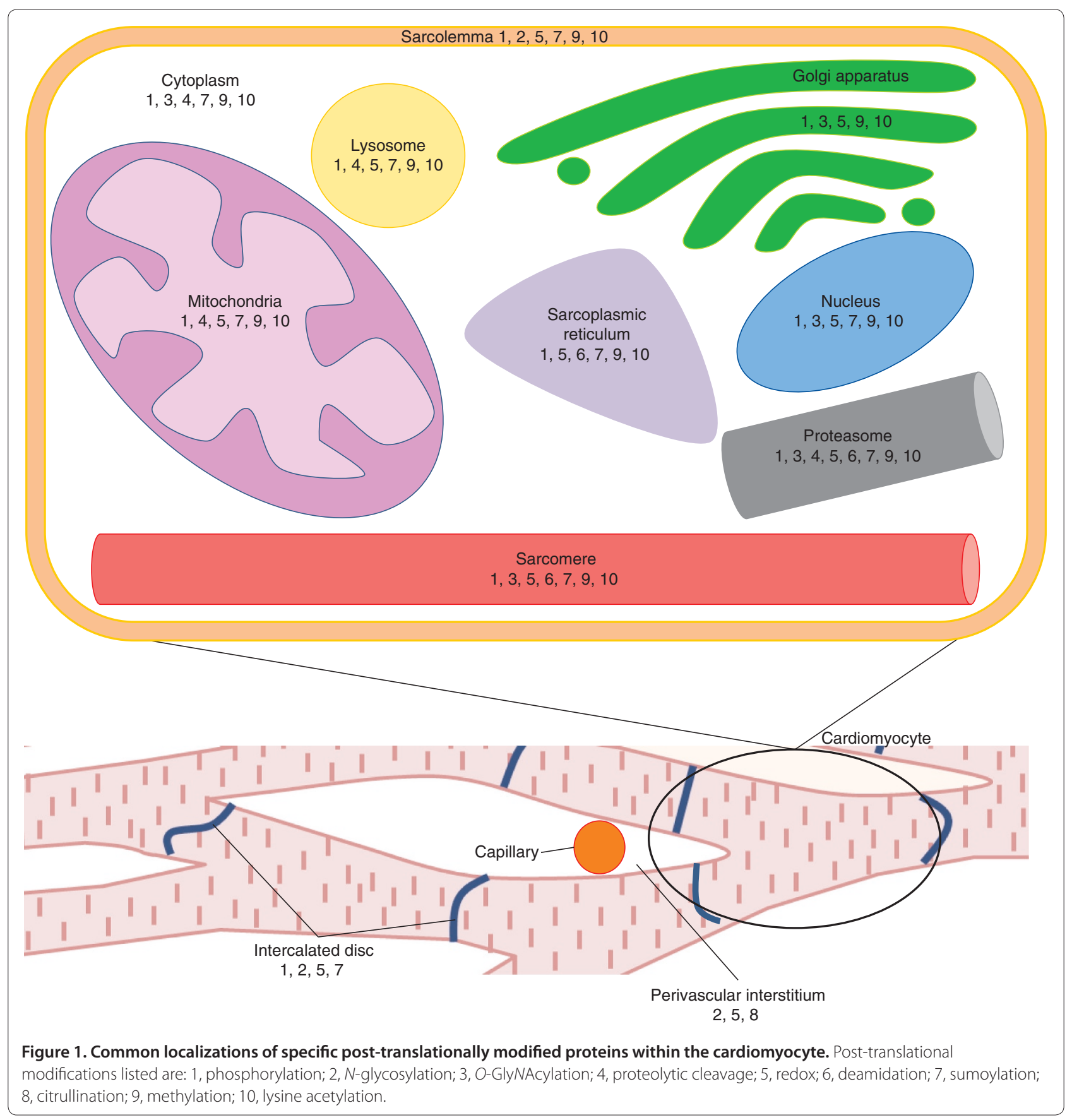

functional groups. Additionally, modifications can be induced by the action of proteases that cleave polypeptides to generate new functional subunits or degrade proteins, resulting in a loss of function. Furthermore, some proteins contain self-regulatory autocatalytic domains; an example is receptor tyrosine kinases, which are auto-phosphorylated following stimulation by a specific environmental trigger. The cellular pool of even a single protein can therefore be a dynamic mixture of its different modified and unmodified forms in various proportions [2], and thus substantial functional diversity can be generated in an often tightly regulated manner [1].

Protein PTM is often the first response to an external stimulus, but aberrant signaling can also contribute to disease. PTM regulation can become dysfunctional through signal amplification or dampening or through abnormal 'PTM crosstalk' [3]. The addition of a nonnative PTM can alter a protein in two ways; firstly, it can lead to biochemical dysfunction, and secondly, it can cause crosstalk in which a native (and potentially 
Table 1. Proteomic methods to enrich and detect post-translational modifications

\begin{tabular}{|c|c|c|c|c|}
\hline Modification & Amino acid & Common motifs & Enrichment methods & Proteomic technologies \\
\hline \multirow[t]{4}{*}{ Phosphorylation } & \multirow[t]{4}{*}{$S, T, Y$} & \multirow[t]{4}{*}{$>320$ possibilities } & Radiolabeling & 2-DE, MS/MS \\
\hline & & & Immobilized metal affinity chromatography & LC-MS/MS \\
\hline & & & $\mathrm{TiO}_{2}$ enrichment & LC-MS/MS \\
\hline & & & IP & 2-DE, LC-MS/MS \\
\hline \multirow[t]{3}{*}{$\mathrm{N}$-glycosylation } & \multirow[t]{3}{*}{ N } & \multirow[t]{3}{*}{$\mathrm{N}-\mathrm{x}-\mathrm{S} / \mathrm{T} / \mathrm{C}$} & Glycan staining & 2-DE, MS/MS \\
\hline & & & Lectin affinity & 2-DE, MS/MS \\
\hline & & & Interaction chemistry & LC-MS/MS \\
\hline \multirow[t]{3}{*}{ O-GlcNAcylation } & \multirow[t]{3}{*}{$S, T$} & \multirow[t]{3}{*}{$P-V-S / T$} & Chemical tagging & LC-MS/MS \\
\hline & & & Affinity isolation & LC-MS/MS \\
\hline & & & $\mathbb{I P}$ & 2-DE, LC-MS/MS \\
\hline \multirow[t]{3}{*}{ Redox } & \multirow[t]{3}{*}{$C, M, Y, W$} & $C / S / T-x-x-C$ & Biotin-switch assay & 2-DE, LC-MS/MS \\
\hline & & \multirow[t]{2}{*}{$C-x-x-C / S / T$} & Thiol disulphide exchange & LC-MS/MS \\
\hline & & & Fluorescent labeling & 2-DE, MS/MS \\
\hline \multirow{3}{*}{$\begin{array}{l}\text { Advanced glycation end } \\
\text { products }\end{array}$} & & & Boronate affinity chromatography & LC-MS/MS \\
\hline & & & $\mathbb{P}$ & 2-DE, MS/MS \\
\hline & & & Western blotting & SDS-PAGE \\
\hline \multirow[t]{2}{*}{ Proteolytic cleavage } & \multirow[t]{2}{*}{$S, C, D, K, R$} & \multirow[t]{2}{*}{ Specific to each protease } & In vitro assays & 2-DE, LC-MS/MS \\
\hline & & & TAILS & LC-MS/MS \\
\hline \multirow[t]{2}{*}{ Deamidation } & \multirow[t]{2}{*}{$N, Q$} & \multirow[t]{2}{*}{$N-G, N-S$} & & Gel electrophoresis \\
\hline & & & & MS \\
\hline \multirow[t]{3}{*}{ Sumoylation } & \multirow[t]{3}{*}{ K } & \multirow[t]{3}{*}{$\Psi-K-x-D / E$} & $\mathbb{P}$ & 2-DE, LC-MS/MS \\
\hline & & & Enzymatic reaction & LC-MS/MS \\
\hline & & & & SDS-PAGE \\
\hline Citrullination & $\mathrm{R}$ & G-x-R-G- $\Psi$ & Chemical derivitization & \\
\hline \multirow[t]{2}{*}{ Methylation } & \multirow[t]{2}{*}{$R, K, Q$} & \multirow{2}{*}{$\begin{array}{l}\text { M-K, R-G-G, R-G-X, R-X-G, } \\
\text { W-X-X-X-R }\end{array}$} & Western blotting & SDS-PAGE \\
\hline & & & $\mathbb{I P}$ & 2-DE, LC-MS/MS \\
\hline Lysine acetylation & K & G-K, K-P & $\mathbb{I P}$ & 2-DE, LC-MS/MS \\
\hline
\end{tabular}

$\Psi$ indicates a hydrophobic residue. 2-DE, two-dimensional gel electrophoresis; IP, immunoprecipitation; LC, liquid chromatography; MS/MS, tandem mass spectroscopy; SDS-PAGE, sodium dodecyl sulfate polyacrylamide gel electrophoresis; TAILS, terminal amine isotopic labeling of substrates.

functionally necessary) PTM cannot be added or removed because of steric hindrance caused by an inhibitory modification at a structurally proximal amino acid. The complexities of PTM in physiological and pathophysiological states are therefore of great significance.

Analysis of PTMs on a large scale has traditionally been difficult because of their generally low abundance [4] and labile nature [5]. Enrichment strategies, such as subcellular fractionation [6] and PTM-focused approaches have now been developed for many PTMs (Table 1), and these have been most successful when combined with the separation power of liquid chromatography and the sensitivity and resolution of mass spectrometry (MS) [1]. These technologies have now provided a window into the ability of PTMs to decorate proteins. Many of these studies have thus provided vast in silico libraries of modified proteins and the sites at which modification can occur [7-13]. Several recent reviews have discussed the 
Table 2. Post-translational modifications in heart disease

\begin{tabular}{|c|c|c|c|c|}
\hline Modification & Stability & Disease state & Proteins investigated & Tissue origin \\
\hline \multirow[t]{3}{*}{ Phosphorylation } & Transient, reversible & Ischemia/reperfusion & JNK [24] & Rattus rattus \\
\hline & & & JAK2-STAT3 [25] & Mus musculus \\
\hline & & & FAK [26] & Mus musculus \\
\hline \multirow[t]{4}{*}{$\mathrm{N}$-glycosylation } & Stable, reversible & Myocardial infarction & Whole proteome [36] & Rattus rattus \\
\hline & & Marfan's syndrome & Fibrilin-1 [39] & Homo sapiens \\
\hline & & Dilated cardiomyopathy & Dolichol kinase [40] & Homo sapiens \\
\hline & & Cardiac conductance disorders & Sodium channel [37] & Mus musculus \\
\hline \multirow[t]{2}{*}{ O-GlcNAcylation } & Transient, reversible & Ischemic cell death & Proteins of the hexosamine biosynthesis pathway [53] & Rattus rattus \\
\hline & & & mitochondrial permeability transition pore [56] & Rattus rattus \\
\hline
\end{tabular}

use of high-throughput techniques to resolve the contribution of the proteome to vascular disease [14-17]. We therefore focus here on the role of PTM in heart disease.

\section{Enzymatically mediated, reversible post-translational modifications}

A diverse collection of enzymatic and reversible modifiers of proteins exists, but for the purpose of this review we will concentrate on phosphorylation, glycosylation ( $N$ - and $O$-linked), lysine acetylation, sumoylation (via addition of small ubiquitin-like modifier (SUMO)) and citrullination (or deimination).

Phosphorylation is now a well-characterized PTM, with many large-scale studies having been conducted in a wide variety of cell types and tissues since 2006 [13,1822]. Over 500 kinases are predicted to be encoded by the human genome [23], 200 of which have been implicated in heart disease [24-26], as reviewed previously [27,28] (Table 2). The tools of phosphoproteomics are being used to define the targets of these kinases, including of novel kinases of poorly defined function [29] such as epsilonprotein kinase $\mathrm{C}$, which protects animal hearts from ischemic injury [30]. Hydrogen-peroxide-induced stress in rat cardiomyocytes has also been shown to induce an increase in tyrosine phosphorylation that is mediated, at least partially, by Src kinase [31].

Phosphorylation can alter the conformation of target proteins, resulting in activation or inactivation of function. Current estimates suggest that as many as 500,000 sites can be phosphorylated on between $10 \%$ and $50 \%$ of the 23,000 proteins in the human genome [32]. Addition of the phosphate group can also recruit (or repel) target proteins, allowing cascades to commence from a single initiator and environmental stimulus. Such signal transduction pathways are crucial in acute cardiac pathologies, such as ischemia/reperfusion (I/R), or indeed cardioprotection where the time-frame for injury or protection is too short to be mediated by large changes in protein abundance. Therefore, specific kinase inhibitors (or activators) are of interest as interventions. The specific enrichment strategies used in phosphoproteomics have been reviewed extensively, with a focus on heart disease [27].

Protein glycosylation, unlike many PTMs, refers to various different modifications of different mass and distribution rather than a single predictable type. Glycosylation can involve the addition of simple monosaccharides through to complex branching glycan structures comprising different individual sugar subunits. Its effects can include alteration or mediation of protein folding, protection against proteolytic degradation, defense against mucosal pathogens, cell-cell communication and adhesion, and immunity [33]. Given the number of enzymatic steps required for the addition of sugar moieties, glycosylation is thought to be the most complex PTM, and thus presents particular analytical challenges (Table 1). Addition of glycans can occur en bloc (in which the glycan is synthesized and added to a previously folded protein substrate) or, more rarely, by sequential transfer of single sugars, one by one, to a nascent (or folded) polypeptide. In both cases, the sugars are attached by oligosaccharyltransferases or glycosyltransferases. Attached glycans can also be modified to add further structural diversity, including sulfation at mannose and $\mathrm{N}$-acetylglucosamine (GlcNAc) residues in extracellular matrix proteoglycans, addition and acetylation of sialic acid, and phosphorylation, such as on mannose 6-phosphate to ensure correct trafficking to lysosomes [34].

$N$-glycosylation is a complex biochemical process that is initiated in the cytoplasm, where sugars are synthesized from nucleotide-derived precursors and then transferred into the endoplasmic reticulum, where further glycan assembly occurs. Once the core 14-mer $N$-glycan is complete, it is transferred by an oligosaccharyltransferase to asparagine residues within the sequence motif Asn- $\mathrm{x}-$ Ser/Thr (where $\mathrm{x}$ is not proline). Further trimming and 
maturation, including addition and subtraction of sugars from the core glycan, occurs in the Golgi apparatus. Once complete, the nascent unfolded glycoprotein is generally transferred to the cell surface or extracellular space, and thus analytical techniques for the enrichment of $N$ glycoproteins are particularly efficient for capture of the plasma membrane sub-proteome [35]. Changes in $N$ linked glycans have been observed in cardiac conductance disorders, in heart failure and during remodeling in response to myocardial infarction [36-38] (Table 2). Typically, however, $N$-linked glycosylation would not be expected to change significantly in acute cardiac pathologies, and it still remains unclear whether this modification has a role in chronic disease.

Although little work has been done in this area, $\mathrm{N}$ glycosylation of fibrillin-1 has been associated with the genetic defect responsible for Marfan syndrome, which results in valve and aorta defects [39]. In addition, autosomal recessive dilated cardiomyopathy has been implicated as a congenital disorder of glycosylation in individuals with mutations in dolichol kinase, an essential enzyme in the biosynthesis of glycan precursors [40]. These patients demonstrate $\mathrm{N}$-glycosylation deficiency and abnormal mannosylation of the laminin-binding extracellular matrix protein $\alpha$-dystroglycan. Additional diseases beyond the classical congenital disorder of glycosylation are now thought to exist [41]. Proteomics, and glycoproteomics in particular, offers the potential to 'type' such diseases by using the diverse chemical properties of the various sugar moieties to determine those absent on a proteome-wide scale in these patients.

Proteomic investigation of mammalian $N$-linked glycans can be technically challenging given the heterogeneity of the modification and the potential size of the PTM. Enrichment strategies allow the effective capture of glycopeptides [36,42-44]; however, the labile nature of glycosidic bonds, and the generally large mass of the modification, renders tandem MS approaches problematic. The field is therefore often divided into two: release and study of the diverse glycan structures without reference to the proteins from which they were derived, and release of the glycan and analysis of the formerly glycosylated peptide(s). Key to identifying the site of glycosylation is the presence of the $N$-linked consensus motif and glycan release facilitated by protein $N$-glycosidase F (PNGase F), which liberates the $N$-glycan and 'tags' the former asparagine modification site by deamidation to an aspartate [45].

The analysis of complex $O$-glycosylation has been comprehensively reviewed recently [46], and little to no information is available concerning a role for complex $O$ glycans in cardiac diseases $[47,48]$. Despite this, potentially the best-characterized cardiac-associated PTM is the $O$ linked attachment of a single $\beta$ - $N$-acetylglucosamine
(O-GlcNAcylation) to serine or threonine residues of predominantly nucleocytoplasmic proteins. O-GlcNAc thus has the potential to compete with phosphorylation for binding sites [49]. This has led to the proposal of $O$ GlcNAc-phosphate crosstalk (see below), although there are currently few examples of reciprocal regulation at identical sites and the functional basis (for example, which PTM is the positive and which is the negative regulator of function) for those that have been identified is generally not known.

$O$-GlcNAc attachment and removal are mediated through the actions of $O$-GlcNAc transferase and $O$ GlcNAcase, respectively. Unlike phosphorylation, for which many kinases and phosphatases act either specifically or in large cascades through signal amplification, these two enzymes are currently the only identified mediators of the O-GlcNAc PTM. O-GlcNAcylation has been identified as a PTM of proteins involved in nuclear transport, translation and transcription, cytoskeletal organization, proteasomal degradation, and apoptosis [50,51]. Consequently, it regulates both positive and negative processes in the cardiovascular system [52] (Table 2). Transient increases in $O$-GlcNAc provide cardioprotection against myocardial ischemia [53-55] and alter the formation of mitochondrial permeability transition pores during $\mathrm{Ca}^{2+}$ overload [56]. Conversely, the chronic increase of $\mathrm{O}$-GlcNAc observed in diabetes has been linked with adverse cardiac symptoms, including hypertrophy [57] and contractile dysfunction [58]. The physiological distinction between these elevations of $O$-GlcNAc may be related to interplay with phosphorylation [55]. For this reason, proteomic investigations of $O$ GlcNAcylation use high-throughput approaches similar to those employed for phosphorylation (Table 1).

Lysine acetylation is an enzymatic and reversible regulatory PTM that is added by histone acetyltransferases (HATs) and reversed by histone deacetylases (HDACs). It has been shown to influence gene expression, metabolic processes and chromatin remodeling [59-61]. Irreversible acetylation also occurs on the amino termini of many proteins. A major family of deacetylases is the sirtuins (SIRTs), which are class III HDACs that require NAD for activity [62-64]. The SIRTs have been closely implicated in both protection against and generation of cardiac disease [65-68] (Table 2). SIRT1 and SIRT7 protect cardiomyocytes from oxidative stressmediated cell death and age-related degeneration [69]. SIRT2 deacetylase inhibition is protective against I/R injury, because SIRT2 binds receptor interacting protein-3 (RIP3), which is part of a necrosis-promoting complex stimulated by tumor necrosis factor $\alpha$ [70]. Conversely, however, SIRT1 inhibition ameliorates SIRT1-associated cardioprotection against I/R [67]. It is clear that the SIRTs are crucial in cardiac diseases, although the mechanism 
of this action, and the proteins through which these phenotypes are mediated, remain largely to be determined.

Proteomics approaches based on MS have recently begun to define the extent of lysine acetylation or deacetylation on a systems-wide level [7,71], revealing a vast level of potential regulation on a scale comparable to protein phosphorylation. Evidence of crosstalk between these modifications through alterations to proteinprotein interactions has also been observed [71]. Targets of specific SIRT forms (such as SIRT3 [72]) are now also being investigated such that both the function of individual SIRTs and their associations with disease can be elucidated. Proteome-wide studies have typically used the specificity of anti-lysine-acetylation antibodies for protein or peptide immunoprecipitation, among other methodologies [73] (Table 1).

Proteins modified with SUMO that is covalently attached to targets in an ATP-dependent manner include many regulatory proteins and proteins found in the nucleus and nuclear pore complex [74,75]. Sumoylation is mediated by the activities of several enzymes, including the SUMO protease, activating and conjugating enzymes, and a SUMO protein ligase, responsible for SUMO addition. Sumoylation occurs in a consensus motif consisting of a hydrophobic residue (valine, isoleucine, leucine, methionine, phenylalanine, proline or cysteine) followed by lysine (the site of the attachment), then any amino acid and then glutamate or glutamine ( $\Psi$-Lys- $\mathrm{x}-$ Glu/Gln); however, several examples of non-conforming sumoylation events and even examples in which the motif is reversed have been identified. Sumoylation seems to regulate several diverse activities, including the cell cycle, DNA repair, localization, chromatin remodeling and the heat shock response [76].

The SUMO pathway is central in the regulation of cardiac gene activity and heart development [77], particularly in cardiogenesis [78] and ion channel modulation $[79,80]$, with defective sumoylation leading to congenital heart defects $[81,82]$. SUMO1 deletion in mice and overexpression of the SUMO protease SENP2, which removes SUMO, both result in cardiac dysfunction and heart defects [81]. In addition, modulation of sarco-endoplasmic reticulum $\mathrm{Ca}^{2+}$ ATPase 2a (SERCA2a) activity by SUMO1 has been demonstrated in heart failure [83]. SERCA2a is sumoylated at lysines 480 and 585 , in a process that is required for ATPase activity and stability of the protein [84]. Sumoylation is significantly reduced in failing hearts, and downregulation of SUMO1 resulted in accelerated pressure-overload-induced deterioration of cardiac function accompanied by decreased SERCA2a activity [84].

Sumoylation can be targeted through the use of antiSUMO antibodies or hexahistidine-tagged or signaturetagged SUMO [85] in immunoprecipitation experiments coupled with MS [74] or western blotting of target proteins [86]. His-tagged SUMO with an inserted carboxyterminal tryptic cleavage site has also been shown to facilitate MS identification of SUMO-modified proteins [87] (Table 1).

Finally, citrullination, or deimination, is the posttranslational conversion of arginine to citrulline that is catalyzed by $\mathrm{Ca}^{2+}$-dependent peptidylarginine deiminases (PADs), of which there are up to six predicted in the human genome [88]. Citrullination alters the structurefunction relationship by changing the local charge and hydrophobicity from the basic arginine to neutral. Although our understanding of this modification is still in its infancy, an association with rheumatoid arthritis [89] has been established (and indeed tests for citrullinated protein can be used for diagnosis), and one or more PADs are either overexpressed or show increased enzymatic activity in other diseases, including multiple sclerosis (myelin basic protein can be citrullinated) and Alzheimer's disease (reviewed in [88]). Although limited work has been conducted on citrullination and cardiac disease outside the context of rheumatoid arthritis, a recent study by Giles et al. [90] determined that PAD1 to PAD3 and PAD6 are expressed in cardiomyocytes, and that citrullination is increased in the myocardial interstitium of patients with rheumatoid arthritis. These authors [90] speculated that elevated citrullination might be a link between arthritis and heart failure that is more commonly observed in these patients. Analytical approaches with high resolution are needed to identify the targets of this PTM. Given that citrullination alters arginine, which is recognized by trypsin, there is scope to directly target the modification in high-throughput approaches. The state of the art in analysis of citrullination in combination with gel electrophoresis, MS and immunodetection has been reviewed recently [91].

\section{Chemically mediated and irreversible post-translational modifications}

Some PTMs are irreversible and caused by chemical processes rather than being controlled by enzymes; the most frequently seen examples are glycation and deamidation. Glycation is the non-enzymatic process of sugar deposition onto proteins or lipids. In the absence of enzymatic control, glycation may have serious implications for the physiological function of proteins. Advanced glycation end products (AGE) not only indicate hyperglycemia, but also represent cumulative metabolic burden, oxidative stress and inflammation [92,93]. Activated cell surface AGE receptors (RAGE) trigger downstream proinflammatory pathways by regulating cytokine production and transcription factors, and they also induce oxidative stress [94,95]. Numerous kinase-regulated pathways also undergo co-activation with AGE receptor 
induction, including mitogen-activated protein kinases [96]. AGE-modified proteins have been detected within myocardial fibers $[97,98]$ and the numbers of such proteins have been shown to correlate with the severity of coronary heart disease [99]. A strong relationship between cardiac disease and overall AGE levels has been demonstrated, with elevated AGE content correlating with poor outcome as shown by adverse cardiac events in patients after cardiac surgery [100]. AGE levels are also a strong predictor for heart failure and new cardiac events [101-103]. Enrichment of AGE-modified proteins before MS is of interest for the detection of new biomarkers [104] (Table 1).

Deamidation is a non-enzymatic process in which removal of an amide converts glutamine and asparagine to glutamate and aspartate, respectively. Deamidation has long been suggested as a form of molecular clock because of its association with protein aging and lifespan [105]. The best studied example of the importance of deamidation in protein function and lifetime is in the eye lens crystallins, which are long-lived proteins whose deamidation progressively occurs during life, resulting in aggregation and cataract formation [106]. Deamidation is influenced by flanking residues, in particular the amino acid carboxy-terminal to the asparagine, which is commonly a glycine or serine [36]. In cardiac tissue, deamidation events have not been studied in depth. Deamidation of the extra large Bcl-2 family protein, $\mathrm{Bcl}-\mathrm{X}(\mathrm{L})$, was found to occur in wild-type mice after myocardial infarction and to sensitize cells to apoptosis through enhanced Bcl-2-associated X protein (BAX) activity. This deamidation was reduced in a dominantnegative mutant of the kinase p38, suggesting that p38 may promote cardiomyocyte apoptosis through $\mathrm{Bcl}-\mathrm{X}(\mathrm{L})$ deamidation [107]. Other studies have shown that deamidated myosin light chain 2 undergoes proteolysis during reperfusion injury post-ischemia between the deamidation site and flanking serine residue [108]. Few other studies have been attempted, most likely due to the lack of a specific enrichment approach for this most neglected of PTMs (Table 1).

\section{Proteolysis, an enzyme-mediated, irreversible post-translational modification}

Cellular processes including antigen processing, apoptosis and signaling use proteases to remove unfolded or incorrectly folded protein substrates, to generate subunits from precursor proteins and to remove potentially toxic functions [109]. Because unregulated protease activity has the potential to be highly damaging, proteases are tightly controlled by sequestration into subcellular compartments, such as proteasomes or lysosomes, by translation as stable inactive precursors (zymogens), and/ or by activity being limited to a specific $\mathrm{pH}$ range or in the presence of specific co-factors (such as $\mathrm{Ca}^{2+}$ ) [110]. Disease processes resulting in incorrect localization or inappropriate activation can have dramatic consequences for the functional stability of the cell, and therefore many therapeutic targets are proteases [109]. Of the more than 500 proteases in the human genome [110], more than $90 \%$ fall into one of four categories: serine proteases, cysteine proteases, aspartate proteases and zinc metalloproteases. In the cardiovascular system, proteases are involved in blood pressure regulation, coagulation and thrombosis, and inflammation, and have been associated with hypertension, heart failure and myocardial infarction $[108,111,112]$. Pathophysiological processes, such as necrosis, induce protease activity; for example, cardiac troponin I is proteolysed following acute myocardial infarction, with circulating levels of fragmented cardiac troponin I the gold-standard marker of irreversible damage in acute coronary syndromes.

Identification of the targets of aberrant protease activity remains a technical challenge. Historically, twodimensional gel electrophoresis technology was the most effective approach for visualizing cleaved forms of target proteins. In recent times, the development of terminal amine isotopic labeling of substrates (TAILS [113-115]) and amino-terminal oriented mass spectrometry of substrates (ATOMS [116]) has allowed the advent of 'degradomics', whereby identification of cleavage sites can be performed in a gel-free manner that is compatible with tandem MS. This amino- and carboxy-terminal degradomics approach has been used to identify new substrates of proteases, in particular of matrix metalloproteinases [117-119].

\section{Modification of proteins by redox signaling and oxidative stress}

Reactive oxygen and nitrogen species (ROS and RNS, respectively), which are generated as a byproduct of many biochemical processes or as a result of environmental oxidative stress, cause specific and both reversible (signaling) and irreversible (oxidative damage) oxidative modifications of biomolecules, including proteins, lipids and DNA. I/R is thought to be an ROS-associated disease because of the large influx of free radicals seen in the first 5 to 10 minutes of reperfusion [120]. Although almost all amino acids can be redox modified, the most likely target of both reversible and irreversible modification is cysteine [121]. Cysteine residues can be oxidized to intraand inter-protein disulfides or reversibly over-oxidized to cysteine sulfenic acid, both of which are recovered by the actions of reductases; and they can be irreversibly oxidized to cysteine sulfinic and sulfonic acids, which impede protein function and may target proteins for degradation. ROS are derived from many sources, both intracellular and extracellular, including NADPH and 
NADH oxidases, which generate signaling ROS for the regulation of cell differentiation, proliferation, migration and survival in the myocardium [122,123]. Other major sources of ROS or RNS in the heart include the mitochondrial electron transport chain, metabolic enzymes, and nitric oxide synthases [124]. Redox regulation mediates both detrimental processes [124] and protective cellular pathways [125].

ROS signaling in the myocardium has been extensively reviewed [123,126-128], but an equally significant role has been suggested for RNS generated by nitric oxide and peroxynitrite [129]. $S$-nitrosylation is a reversible, labile PTM that occurs on free cysteine and is thus thought to be an important regulator or redox switch $[130,131]$. Reversible cysteine modifications, predominantly disulfides, cysteine sulfenic acid and $S$-nitrosylation, can be enriched at the protein level through the use of the biotin-switch assay [131] or thiol disulfide exchange chemistry [132].

\section{Post-translational modification interplay and crosstalk}

Although individual PTMs are clearly crucial in mediating protein structure-function relationships, until recently the potential for different modifications to influence each other through cooperation or competition had not been explored. Such PTM crosstalk has the potential to act as a completely new level of cellular regulation, allowing rapid changes in function without the requirement for genomic activation. The basis for crosstalk includes three levels (Figure 2): competition for the same site; modification that changes the structure to make a second site accessible or inaccessible to the modifying enzyme for another PTM; or direct modification of the modifying enzyme of the second PTM (such as $O$-GlcNAcylation of a kinase activating or inhibiting function). Crosstalk has been explored in histones as part of the chromatin code [133], but it is evident in many other biological systems. One of the first examples of potential PTM crosstalk came in examining the potential sites of $O$-GlcNAc or phosphorylation modification, because both PTMs target serine and threonine residues [55]. When taken with the fact that both are dynamic and transient, it is tempting to hypothesize that these PTMs compete for sites of regulation. However, the extent of interplay and the regulatory mechanisms behind such crosstalk remain elusive $[134,135]$. Superficial elevation of O-GlcNAcylation with the addition of multiple OGlcNAcase inhibitors in mouse embryonic fibroblasts resulted in reciprocal regulation of phosphorylation at over 400 sites ( 280 of which showed reduced phosphorylation), providing evidence for crosstalk or competition between protein kinases and $O$-GlcNAc transferase [136]. Adding a further level of complexity to the

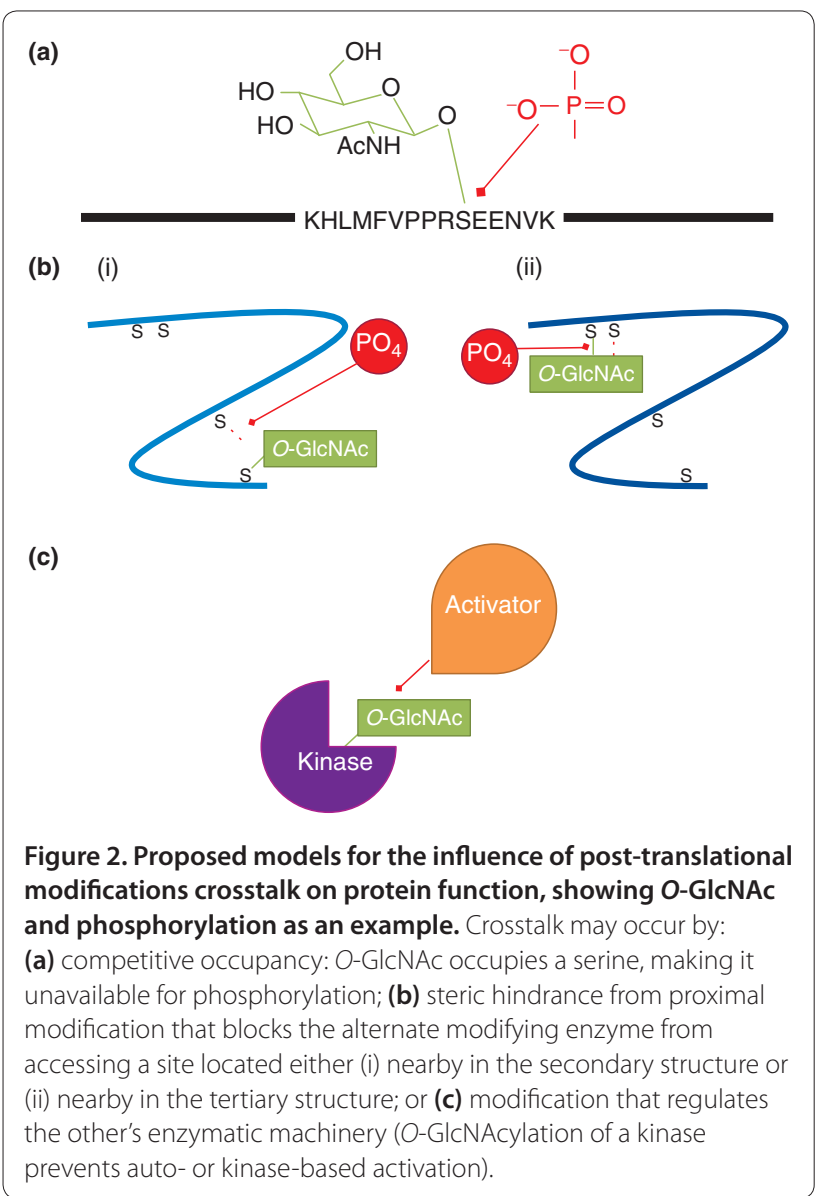

relationship between $O$-GlcNAc and phosphate is the recent discovery of a single O-GlcNAc-6-phosphate modification [137] that can be attached to multiple proteins [138].

Crosstalk between other modifications has also been suggested, for example between sumoylation and phosphorylation. Large-scale sumoylation investigations showed the lysine site of SUMO attachment spaced four residues from a phosphorylated serine in a significant proportion of the sumoylated proteins $[139,140]$. Phosphorylation and lysine acetylation also seem to crosstalk, for example AMP-activated protein kinase and the SIRT family [141]. Crosstalk may also be a signal for degradation: in I/R injury, myosin light chain 2 is degraded between a phosphorylated serine and a deamidated asparagine, showing that three PTMs can occur within two amino acids of each other [108].

\section{Conclusions}

The widespread nature and diversity of protein PTMs and the sheer number of enzymes encoded within the human genome that are predicted to modify proteins strongly implies that there is a level of previously unknown regulation within cells. We have concentrated 
here on only a handful of reasonably well-characterized PTMs and those that seem to be of emerging significance in cardiac disease, but it would be equally possible to discuss additional modifications, such as arginine and lysine methylation, mediated by protein methyltransferases and demethylases (reviewed in [142-144]). Ubiquitination alone could be the subject of several reviews (a role in myocardial ischemia has been reviewed recently [145]). High-throughput and high-resolution proteomics approaches have facilitated the discovery of these modifications and added large swathes of site-specific information to protein databases. We consider that PTM crosstalk will eventually be viewed as a complex and directed regulatory mechanism used by cells in a manner analogous to microRNA post-transcriptional regulation. The potential for elucidating these mechanisms will further aid in our ability to understand cellular mechanisms of disease and provide targeted strategies for disease intervention.

\section{Abbreviations}

AGE, advanced glycation end products; GICNAc, N-acetylglucosamine; I/R, ischemia/reperfusion; MS, mass spectrometry; PAD, peptidylarginine deiminase; PTM, post-translational modification; RNS, reactive nitrogen species; ROS, reactive oxygen species; SERCA2a, sarco-endoplasmic reticulum $\mathrm{Ca}^{2+}$ ATPase 2a; SIRT, sirtuin; SUMO, small ubiquitin-like modifier.

\section{Acknowledgments}

This work was facilitated by grants from the National Health and Medical Research Council (NHMRC) of Australia. MYW is the recipient of an Australian Research Council Discovery Early Career Research Award (DECRA). KAL is the recipient of an Australian Postgraduate Award.

\section{Competing interests}

The authors declare that they have no competing interests.

Published: 28 February 2013

\section{References}

1. Mann M, Jensen O: Proteomic analysis of post-translational modifications. Nat Biotech 2003, 21:255-261.

2. Wu R, Haas W, Dephoure N, Huttlin EL, Zhai B, Sowa ME, Gygi SP: A largescale method to measure absolute protein phosphorylation stoichiometries. Nat Methods 2011, 8:677-683.

3. Butkinaree C, Park K, Hart GW: O-linked beta-N-acetylglucosamine (O-GlcNAc): Extensive crosstalk with phosphorylation to regulate signaling and transcription in response to nutrients and stress. Biochim Biophys Acta 2010, 1800:96-106.

4. Seo J, Jeong J, Kim YM, Hwang N, Paek E, Lee K-J: Strategy for comprehensive identification of post-translational modifications in cellular proteins, including low abundant modifications: application to glyceraldehyde-3-phosphate dehydrogenase. J Proteome Res 2008, 7:587-602.

5. Mikesh LM, Ueberheide B, Chi A, Coon JJ, Syka JEP, Shabanowitz J, Hunt DF: The utility of ETD mass spectrometry in proteomic analysis. Biochim Biophys Acta 2006, 1764:1811-1822.

6. White MY, Edwards AVG, Cordwell SJ, van Eyk JE: Mitochondria: a mirror into cellular dysfunction in heart disease. Prot Clin App/ 2008, 2:845-861.

7. Lundby A, Lage K, Weinert BT, Bekker-Jensen DB, Secher A, Skovgaard T, Kelstrup CD, Dmytriyev A, Choudhary C, Lundby C, Olsen JV: Proteomic analysis of lysine acetylation sites in rat tissues reveals organ specificity and subcellular patterns. Cell Rep 2012, 2:419-431.

8. BockT, Moest H, Omasits U, Dolski S, Lundberg E, Frei A, Hofmann A, BauschFluck D, Jacobs A, Krayenbuehl N, Uhlen M, Aebersold R, Frei K, Wollscheid B: Proteomic analysis reveals drug accessible cell surface $\mathrm{N}$-glycoproteins of primary and established glioblastoma cell lines. J Proteome Res 2012 11:4885-4893.

9. Wagner SA, Beli P, Weinert BT, Schölz C, Kelstrup CD, Young C, Nielsen ML, Olsen JV, Brakebusch C, Choudhary C: Proteomic analyses reveal divergent ubiquitylation site patterns in murine tissues. Mol Cell Proteomics 2012, 11:1578-1585

10. Lundby A, Secher A, Lage K, Nordsborg NB, Dmytriyev A, Lundby C, Olsen JV: Quantitative maps of protein phosphorylation sites across 14 different rat organs and tissues. Nat Commun 2012, 3:876.

11. Kunz RC, McAllister FE, Rush J, Gygi SP: A high-throughput, multiplexed kinase assay using a benchtop orbitrap mass spectrometer to investigate the effect of kinase inhibitors on kinase signaling pathways. Anal Chem 2012, 84:6233-6239.

12. Kim W, Bennett EJ, Huttlin EL, Guo A, Li J, Possemato A, Sowa ME, Rad R, Rush J, Comb MJ, Harper JW, Gygi SP: Systematic and quantitative assessment of the ubiquitin-modified proteome. Mol Cell 2011, 44:325-340.

13. Huttlin EL, Jedrychowski MP, Elias JE, Goswami T, Rad R, Beausoleil SA, Villén J, Haas W, Sowa ME, Gygi SP: A tissue-specific atlas of mouse protein phosphorylation and expression. Cell 2010, 143:1174-1189.

14. Didangelos A, Stegemann C, Mayr M: The -omics era: proteomics and lipidomics in vascular research. Atherosclerosis 2012, 221:12-17.

15. Senis $Y$, Garcia A: Platelet proteomics: state of the art and future perspective. Methods Mol Biol 2012, 788:367-399.

16. Döring $Y$, Noels $H$, Weber $C$ : The use of high-throughput technologies to investigate vascular inflammation and atherosclerosis. Arterioscler Thromb Vasc Biol 2012, 32:182-195.

17. Di Michele M, Van Geet C, Freson K: Recent advances in platelet proteomics. Expert Rev Proteomics 2012, 9:451-466.

18. Johnson C, Tinti M, Wood NT, Campbell DG, Toth R, Dubois F, Geraghty KM Wong BHC, Brown LJ, Tyler J, Gernez A, Chen S, Synowsky S, MacKintosh C: Visualization and biochemical analyses of the emerging mammalian 14-3-3-phosphoproteome. Mol Cell Proteomics 2011, 10:M110.005751.

19. Stone MD, Chen X, McGowan T, Bandhakavi S, Cheng B, Rhodus NL, Griffin TJ: Large-scale phosphoproteomics analysis of whole saliva reveals a distinct phosphorylation pattern. J Proteome Res 2011, 10:1728-1736.

20. Zhao X, León IR, Bak S, Mogensen M, Wrzesinski K, Højlund K, Jensen ON: Phosphoproteome analysis of functional mitochondria isolated from resting human muscle reveals extensive phosphorylation of inner membrane protein complexes and enzymes. Mol Cell Proteomics 2011, 10:M110.000299.

21. Rinschen MM, Yu M-J, Wang G, Boja ES, Hoffert JD, Pisitkun T, Knepper MA: Quantitative phosphoproteomic analysis reveals vasopressin V2-receptordependent signaling pathways in renal collecting duct cells. Proc Natl Acad SciUSA 2010, 107:3882-3887.

22. Olsen JV, Blagoev B, Gnad F, Macek B, Kumar C, Mortensen P, Mann M: Global, in vivo, and site-specific phosphorylation dynamics in signaling networks. Cell 2006, 127:635-648.

23. Manning G, Whyte D, Martinez R, Hunter T, Sudarsanam S: The protein kinase complement of the human genome. Science 2002, 298:1912-1934.

24. Chambers JW, Pachori A, Howard S, lqbal S, LoGrasso PV: Inhibition of JNK mitochondrial localization and signaling is protective against ischemiareperfusion injury in rats. J Biol Chem 2013, 288:4000-4011.

25. Das A, Salloum FN, Durrant D, Ockaili R, Kukreja RC: Rapamycin protects against myocardial ischemia-reperfusion injury through JAK2-STAT3 signaling pathway. J Mol Cell Cardio/ 2012, 53:858-869.

26. Cheng Z, DiMichele LA, Hakim ZS, Rojas M, Mack CP, Taylor JM: Targeted focal adhesion kinase activation in cardiomyocytes protects the heart from ischemia/reperfusion injury. Arterioscler Thromb Vasc Bio/ 2012, 32:924-933.

27. Edwards AVG, Cordwell SJ, White MY: Phosphoproteomic profiling of the myocyte. Circ Cardiovasc Genet 2011, 4:575

28. Rose BA, Force T, Wang Y: Mitogen-activated protein kinase signaling in the heart: angels versus demons in a heart-breaking tale. Physiol Rev 2010, 90:1507-1546.

29. Kettenbach AN, Schweppe DK, Faherty BK, Pechenick D, Pletnev AA, Gerber SA: Quantitative phosphoproteomics identifies substrates and functional modules of Aurora and Polo-like kinase activities in mitotic cells. Sci Signal 2011, 4:rs5.

30. Budas G, Costa HM Jr, Ferreira JCB, Teixeira da Silva Ferreira AE, Perales J, Krieger JEE, Mochly-Rosen D, Schechtman D: Identification of $\varepsilon P K C$ targets during cardiac ischemic injury. Circ J 2012, 76:1476-1485.

31. Chou H-C, Chen Y-W, Lee T-R, Wu F-S, Chan H-T, Lyu P-C, Timms JF, Chan H-L: 
Proteomics study of oxidative stress and Src kinase inhibition in $\mathrm{H} 9 \mathrm{C} 2$ cardiomyocytes: a cell model of heart ischemia-reperfusion injury and treatment. Free Radic Biol Med 2010, 49:96-108.

32. Cohen P: The regulation of protein function by multisite phosphorylation-a 25 year update. Trends Biochem Sci 2000, 25:596-601.

33. Moremen KW, Tiemeyer M, Nairn AV: Vertebrate protein glycosylation: diversity, synthesis and function. Nat Rev Mol Cell Biol 2012, 13:448-462.

34. Kornfeld S: A fascination with sugars. Mol Biol Cell 2010, 21:3773-3775.

35. Cordwell SJ, Thingholm TE: Technologies for plasma membrane proteomics. Proteomics 2010, 10:611-627.

36. Parker BL, Palmisano G, Edwards AVG, White MY, Engholm-Keller K, Lee A, Scott NE, Kolarich D, Hambly BD, Packer NH, Larsen MR, Cordwell SJ: Quantitative N-linked glycoproteomics of myocardial ischemia and reperfusion injury reveals early remodeling in the extracellular environment. Mol Cell Proteomics 2011, 10:M110.006833.

37. Ufret-Vincenty CA, Baro DJ, Lederer WJ, Rockman HA, Quinones LE, Santana LF: Role of sodium channel deglycosylation in the genesis of cardiac arrhythmias in heart failure. J Biol Chem 2001, 276:28197-28203.

38. Splawski I, Timothy KW, Tateyama M, Clancy CE, Malhotra A, Beggs AH, Cappuccio FP, Sagnella GA, Kass RS, Keating MT: Variant of SCN5A sodium channel implicated in risk of cardiac arrhythmia. Science 2002, 297:1333-1336.

39. Lönnqvist L, Karttunen L, Rantamäki T, Kielty C, Raghunath M, Peltonen L: A point mutation creating an extra $\mathrm{N}$-glycosylation site in fibrillin-1 results in neonatal Marfan syndrome. Genomics 1996, 36:468-475.

40. Lefeber DJ, de Brouwer APM, Morava E, Riemersma M, Schuurs-Hoeijmakers JHM, Absmanner B, Verrijp K, van den Akker WMR, Huijben K, Steenbergen G, van Reeuwijk J, Jozwiak A, Zucker N, Lorber A, Lammens M, Knopf C, van Bokhoven H, Grünewald S, Lehle L, Kapusta L, Mandel H, Wevers RA: Autosomal recessive dilated cardiomyopathy due to DOLK mutations results from abnormal dystroglycan O-mannosylation. PLoS Genet 2011, 7:e1002427

41. Hennet T: Diseases of glycosylation beyond classical congenital disorders of glycosylation. Biochim Biophys Acta 2012, 1820:1306-1317.

42. Larsen MR, Jensen SS, Jakobsen LA, Heegaard NHH: Exploring the sialiome using titanium dioxide chromatography and mass spectrometry. Mol Cell Proteomics 2007, 6:1778-1787.

43. McDonald CA, Yang JY, Marathe V, Yen T-Y, Macher BA: Combining results from lectin affinity chromatography and glycocapture approaches substantially improves the coverage of the glycoproteome. Mol Cell Proteomics 2009, 8:287-301.

44. Zhang H, Li X-J, Martin DB, Aebersold R: Identification and quantification of $\mathrm{N}$-linked glycoproteins using hydrazide chemistry, stable isotope labeling and mass spectrometry. Nat Biotech 2003, 21:660-666.

45. Palmisano G, Lendal SE, Engholm-Keller K, Leth-Larsen R, Parker BL, Larsen MR: Selective enrichment of sialic acid-containing glycopeptides using titanium dioxide chromatography with analysis by HILIC and mass spectrometry. Nat Protoc 2010, 5:1974-1982.

46. Jensen PH, Kolarich D, Packer NH: Mucin-type O-glycosylation--putting the pieces together. FEBS $J$ 2010, 277:81-94.

47. Peng J, Jiang J, Wang W, Qi X, Sun X-L, Wu Q: Glycosylation and processing of pro-B-type natriuretic peptide in cardiomyocytes. Biochem Biophys Res Commun 2011, 411:593-598.

48. Chandrasekhar KD, Lvov A, Terrenoire C, Gao GY, Kass RS, Kobertz WR: O-glycosylation of the cardiac I(Ks) complex. J Physiol 2011, 589:3721-3730.

49. Wang Z, Udeshi ND, Slawson C, Compton PD, Sakabe K, Cheung WD, Shabanowitz J, Hunt DF, Hart GW: Extensive crosstalk between O-GlcNAcylation and phosphorylation regulates cytokinesis. Sci Signal2010, 3:ra2.

50. Zachara NE, O'Donnell N, Cheung WD, Mercer JJ, Marth JD, Hart GW: Dynamic O-GIcNAc modification of nucleocytoplasmic proteins in response to stress. A survival response of mammalian cells. J Biol Chem 2004, 279:30133-30142.

51. Zachara NE, Hart GW: Cell signaling, the essential role of O-GlcNAc! Biochim Biophys Acta 2006, 1761:599-617.

52. Marsh SA, Chatham JC: The paradoxical world of protein O-GICNAcylation: a novel effector of cardiovascular (dys)function. Cardiovasc Res 2011, 89:487-488.

53. Liu J, Marchase RB, Chatham JC: Increased O-GIcNAc levels during reperfusion lead to improved functional recovery and reduced calpain proteolysis. Am J Physiol Heart Circ Physiol 2007, 293:H1391- H1399.
54. Fülöp N, Zhang Z, Marchase RB, Chatham JC: Glucosamine cardioprotection in perfused rat hearts associated with increased O-linked $\mathrm{N}$-acetylglucosamine protein modification and altered p38 activation. Am J Physiol Heart Circ Physiol 2007, 292:H2227- H2236.

55. Hart GW, Slawson C, Ramirez-Correa G, Lagerlof O: Cross talk between O-GlcNAcylation and phosphorylation: roles in signaling, transcription, and chronic disease. Annu Rev Biochem 2011, 80:825-858.

56. Ngoh GA, Watson $L$, Facundo HT, Jones SP: Augmented O-GIcNAc signaling attenuates oxidative stress and calcium overload in cardiomyocytes. Amino Acids 2011, 40:895-911.

57. Marsh SA, Dell'Italia L, Chatham JC: Activation of the hexosamine biosynthesis pathway and protein O-GIcNAcylation modulate hypertrophic and cell signaling pathways in cardiomyocytes from diabetic mice. Amino Acids 2011, 40:819-828.

58. Hu Y, Belke D, Suarez J, Swanson E, Clark R, Hoshijima M, Dillmann WH: Adenovirus-mediated overexpression of O-GlcNAcase improves contractile function in the diabetic heart. Circ Res 2005, 96:1006-1013.

59. You L, Nie J, Sun W-J, Zheng Z-Q, Yang X-J: Lysine acetylation: enzymes, bromodomains and links to different diseases. Essays Biochem 2012, 52:1-12

60. Guan K-L, Xiong Y: Regulation of intermediary metabolism by protein acetylation. Trends Biochem Sci 2011, 36:108-116.

61. Norris KL, Lee J-Y, Yao T-P: Acetylation goes global: the emergence of acetylation biology. Sci Signal 2009, 2:pe76.

62. Newman JC, He W, Verdin E: Mitochondrial protein acylation and intermediary metabolism: regulation by sirtuins and implications for metabolic disease. J Biol Chem 2012, 287:42436-42443.

63. Sack MN: The role of SIRT3 in mitochondrial homeostasis and cardiac adaptation to hypertrophy and aging. J Mol Cell Cardiol 2012, 52:520-525.

64. Morris BJ: Seven sirtuins for seven deadly diseases of aging. Free Radic Biol Med 2012

65. Tanno M, Kuno A, Horio Y, Miura T: Emerging beneficial roles of sirtuins in heart failure. Basic Res Cardiol 2012, 107:273.

66. Kawashima T, Inuzuka Y, Okuda J, Kato T, Niizuma S, Tamaki Y, Iwanaga Y, Kawamoto A, Narazaki M, Matsuda T, Adachi S, Takemura G, Kita T, Kimura T, Shioi T: Constitutive SIRT1 overexpression impairs mitochondria and reduces cardiac function in mice. J Mol Cell Cardiol 2011, 51:1026-1036.

67. Nadtochiy SM, Yao H, McBurney MW, Gu W, Guarente L, Rahman I, Brookes PS: SIRT1-mediated acute cardioprotection. Am J Physiol Heart Circ Physiol 2011, 301:H1506-H1512.

68. Nadtochiy SM, Redman E, Rahman I, Brookes PS: Lysine deacetylation in ischaemic preconditioning: the role of SIRT1. Cardiovasc Res 2011, 89:643-649.

69. Chong ZZ, Wang S, Shang YC, Maiese K: Targeting cardiovascular disease with novel SIRT1 pathways. Future Cardiol 2012, 8:89-100.

70. Narayan N, Lee IH, Borenstein R, Sun J, Wong R, Tong G, Fergusson MM, Liu J, Rovira II, Cheng H-L, Wang G, Gucek M, Lombard D, Alt FW, Sack MN, Murphy E, Cao L, Finkel T: The NAD-dependent deacetylase SIRT2 is required for programmed necrosis. Nature 2012, 492:199-204.

71. Choudhary C, Kumar C, Gnad F, Nielsen M, Rehman M, Walther T, Olsen J, Mann M: Lysine acetylation targets protein complexes and co-regulates major cellular functions. Science 2009, 325:834-840.

72. Sol EM, Wagner SA, Weinert BT, Kumar A, Kim H-S, Deng C-X, Choudhary C: Proteomic investigations of lysine acetylation identify diverse substrates of mitochondrial deacetylase sirt3. PLOS ONE 2012, 7:e50545.

73. Mischerikow N, Heck AJR: Targeted large-scale analysis of protein acetylation. Proteomics 2011, 11:571-589.

74. Li T, Evdokimov E, Shen R-F, Chao C-C, Tekle E, Wang T, Stadtman ER, Yang $\mathrm{DCH}$, Chock PB: Sumoylation of heterogeneous nuclear ribonucleoproteins, zinc finger proteins, and nuclear pore complex proteins: a proteomic analysis. Proc Nat/ Acad Sci USA 2004, 101:8551-8556.

75. Matafora V, D'Amato A, Mori S, Blasi F, Bachi A: Proteomics analysis of nucleolar SUMO-1 target proteins upon proteasome inhibition. Mol Cell Proteomics 2009, 8:2243-2255.

76. Flick K, Kaiser P: Proteomic revelation: SUMO changes partners when the heat is on. Science Signaling 2009, 2:pe45.

77. Wang J, Schwartz RJ: Sumoylation and regulation of cardiac gene expression. Circ Res 2010, 107:19-29.

78. Wang J: Cardiac function and disease: emerging role of small ubiquitinrelated modifier. Wiley Interdiscip Rev Syst Biol Med 2011, 3:446-457.

79. Benson MD, Li Q-J, Kieckhafer K, Dudek D, Whorton MR, Sunahara RK, 
Iñiguez-Lluhí JA, Martens JR: SUMO modification regulates inactivation of the voltage-gated potassium channel Kv1.5. Proc Natl Acad Sci USA 2007, 104:1805-1810.

80. Liu H, Zein El L, Kruse M, Guinamard R, Beckmann A, Bozio A, Kurtbay G, Mégarbané A, Ohmert I, Blaysat G, Villain E, Pongs O, Bouvagnet P: Gain-offunction mutations in TRPM4 cause autosomal dominant isolated cardiac conduction disease. Circ Cardiovasc Genet 2010, 3:374-385.

81. Kim EY, Chen L, Ma Y, Yu W, Chang J, Moskowitz IP, Wang J: Enhanced desumoylation in murine hearts by overexpressed SENP2 leads to congenital heart defects and cardiac dysfunction. J Mol Cell Cardio/ 2012, 52:638-649.

82. Kim EY, Chen L, Ma Y, Yu W, Chang J, Moskowitz IP, Wang J: Expression of sumoylation deficient Nkx2.5 mutant in Nkx2.5 haploinsufficient mice leads to congenital heart defects. PLOS ONE 2011, 6:e20803.

83. Schwartz RJ, Yeh ETH: Weighing in on heart failure: the role of SERCA2a SUMOylation. Circ Res 2012, 110:198-199.

84. Kho C, Lee A, Jeong D, Oh JG, Chaanine AH, Kizana E, Park WJ, Hajjar RJ: SUMO1-dependent modulation of SERCA2a in heart failure. Nature 2011, 477:601-605.

85. Blomster HA, Imanishi SY, Siimes J, Kastu J, Morrice NA, Eriksson JE, Sistonen L: In vivo identification of sumoylation sites by a signature tag and cysteinetargeted affinity purification. J Biol Chem 2010, 285:19324-19329.

86. Tatham MH, Rodriguez MS, Xirodimas DP, Hay RT: Detection of protein SUMOylation in vivo. Nat Protoc 2009, 4:1363-1371.

87. Galisson F, Mahrouche L, Courcelles M, Bonneil E, Meloche S, Chelbi-Alix MK Thibault P: A novel proteomics approach to identify SUMOylated proteins and their modification sites in human cells. Mol Cell Proteomics 2011, 10:M1 10.004796.

88. Bicker KL, Thompson PR: The protein arginine deiminases: Structure, function, inhibition, and disease. Biopolymers 2013, 99:155-163.

89. Serra-Bonett N, Rodriguez MA: The swollen joint, the thickened artery, and the smoking gun: tobacco exposure, citrullination and rheumatoid arthritis. Rheumatol Int 2011, 31:567-572

90. Giles JT, Fert-Bober J, Park JK, Bingham CO3, Andrade F, Fox-Talbot K, Pappas D, Rosen A, Van Eyk J, Bathon JM, Halushka MK: Myocardial citrullination in rheumatoid arthritis: a correlative histopathologic study. Arthritis Res Ther 2012, 14:R39.

91. De Ceuleneer M, Van Steendam K, Dhaenens M, Deforce D: In vivo relevance of citrullinated proteins and the challenges in their detection. Proteomics 2012, 12:752-760

92. Zhang Q, Ames JM, Smith RD, Baynes JW, Metz TO: A perspective on the Maillard reaction and the analysis of protein glycation by mass spectrometry: probing the pathogenesis of chronic disease. J Proteome Res 2009, 8:754-769.

93. Singh DK, Winocour P, Farrington K: Oxidative stress in early diabetic nephropathy: fueling the fire. Nat Rev Endocrinol 2011, 7:176-184.

94. Goova MT, Li J, Kislinger T, Qu W, Lu Y, Bucciarelli LG, Nowygrod S, Wolf BM Caliste X, Yan S-F, Stern DM, Schmidt AM: Blockade of receptor for advanced glycation end-products restores effective wound healing in diabetic mice. Am J Pathol 2001, 159:513-525.

95. Basta G, Schmidt AM, De Caterina R: Advanced glycation end products and vascular inflammation: implications for accelerated atherosclerosis in diabetes. Cardiovasc Res 2004, 63:582-592.

96. Yeh CH, Sturgis L, Haidacher J, Zhang XN, Sherwood SJ, Bjercke RJ, Juhasz O, Crow MT, Tilton RG, Denner $L$ : Requirement for $p 38$ and p44/p42 mitogenactivated protein kinases in RAGE-mediated nuclear factor-kappaB transcriptional activation and cytokine secretion. Diabetes 2001, 50:1495-1504

97. Susic D: Cross-link breakers as a new therapeutic approach to cardiovascular disease. Biochem Soc Trans 2007, 35:853-856.

98. Diguet N, Mallat Y, Ladouce R, Clodic G, Prola A, Tritsch E, Blanc J, Larcher J-C, Delcayre C, Samuel J-L, Friguet B, Bolbach G, Li Z, Mericskay M: Muscle creatine kinase deficiency triggers both actin depolymerization and desmin disorganization by advanced glycation end products in dilated cardiomyopathy. J Biol Chem 2011, 286:35007-35019.

99. Colhoun HM, Betteridge DJ, Durrington P, Hitman G, Neil A, Livingstone S, Charlton-Menys V, Bao W, Demicco DA, Preston GM, Deshmukh H, Tan K, Fuller $\mathrm{JH}$ : Total soluble and endogenous secretory receptor for advanced glycation end products as predictive biomarkers of coronary heart disease risk in patients with type 2 diabetes: an analysis from the CARDS trial. Diabetes 2011, 60:2379-2385.
100. Simm A, Wagner J, Gursinsky T, Nass N, Friedrich I, Schinzel R, Czeslik E, Silber RE, Scheubel RJ: Advanced glycation endproducts: a biomarker for age as an outcome predictor after cardiac surgery? Exp Gerontol 2007, 42:668-675.

101. Hartog JWL, Voors AA, Schalkwijk CG, Scheijen J, Smilde TDJ, Damman K, Bakker SJL, Smit AJ, van Veldhuisen DJ: Clinical and prognostic value of advanced glycation end-products in chronic heart failure. Eur Heart $J 2007$ 28:2879-2885.

102. Koyama Y, Takeishi Y, Arimoto T, Niizeki T, Shishido T, Takahashi H, Nozaki N, Hirono O, Tsunoda Y, Nitobe J, Watanabe T, Kubota I: High serum level of pentosidine, an advanced glycation end product (AGE), is a risk factor of patients with heart failure. J Card Fail 2007, 13:199-206.

103. Kilhovd BK, Juutilainen A, Lehto S, Rönnemaa T, Torjesen PA, Hanssen KF, Laakso M: Increased serum levels of advanced glycation endproducts predict total, cardiovascular and coronary mortality in women with type 2 diabetes: a population-based 18 year follow-up study. Diabetologia 2007, 50:1409-1417.

104. Zhang Q, Monroe ME, Schepmoes AA, Clauss TRW, Gritsenko MA, Meng D, Petyuk VA, Smith RD, Metz TO: Comprehensive identification of glycated peptides and their glycation motifs in plasma and erythrocytes of control and diabetic subjects. J Proteome Res 2011, 10:3076-3088.

105. Robinson NE, Robinson AB: Deamidation of human proteins. Proc Natl Acad SciUSA 2001, 98:12409-12413.

106. Hains PG, Truscott RJW: Age-dependent deamidation of lifelong proteins in the human lens. Invest Ophthalmol Vis Sci 2010, 51:3107-3114.

107. Ren J, Zhang S, Kovacs A, Wang Y, Muslin AJ: Role of p38alpha MAPK in cardiac apoptosis and remodeling after myocardial infarction. $J \mathrm{Mol}$ Cell Cardiol 2005, 38:617-623.

108. White MY, Cordwell SJ, McCarron HCK, Tchen AS, Hambly BD, Jeremy RW: Modifications of myosin-regulatory light chain correlate with function of stunned myocardium. J Mol Cell Cardiol 2003, 35:833-840.

109. Overall CM, Blobel CP: In search of partners: linking extracellular proteases to substrates. Nat Rev Mol Cell Biol 2007, 8:245-257.

110. Puente XS, Sánchez LM, Overall CM, López-Otín C: Human and mouse proteases: a comparative genomic approach. Nat Rev Genet 2003, 4:544-558.

111. Klingler D, Hardt M: Targeting proteases in cardiovascular diseases by mass spectrometry-based proteomics. Circ Cardiovasc Genet 2012, 5:265.

112. Müller AL, Dhalla NS: Role of various proteases in cardiac remodeling and progression of heart failure. Heart Fail Rev 2012, 17:395-409.

113. Kleifeld O, Doucet A, auf dem Keller U, Prudova A, Schilling O, Kainthan RK, Starr AE, Foster $\sqcup$, Kizhakkedathu JN, Overall CM: Isotopic labeling of terminal amines in complex samples identifies protein $\mathrm{N}$-termini and protease cleavage products. Nat Biotech 2010, 28:281-288.

114. Kleifeld O, Doucet A, Prudova A auf dem Keller U, Gioia M, Kizhakkedathu JN, Overall CM: Identifying and quantifying proteolytic events and the natural $\mathrm{N}$ terminome by terminal amine isotopic labeling of substrates. Nat Protoc 2011, 6:1578-1611.

115. Schilling O, Barré O, Huesgen PF, Overall CM: Proteome-wide analysis of protein carboxy termini: C terminomics. Nat Methods 2010, 7:508-511.

116. Doucet A, Overall CM: Amino-Terminal Oriented Mass Spectrometry of Substrates (ATOMS) N-terminal sequencing of proteins and proteolytic cleavage sites by quantitative mass spectrometry. Methods Enzymol 2011, 501:275-293

117. Becker-Pauly C, Barré O, Schilling O, auf dem Keller U, Ohler A, Broder C, Schütte A, Kappelhoff R, Stöcker W, Overall CM: Proteomic analyses reveal an acidic prime side specificity for the astacin metalloprotease family reflected by physiological substrates. Mol Cell Proteomics 2011, 10:M111.009233.

118. Prudova A, auf dem Keller U, Butler GS, Overall CM: Multiplex N-terminome analysis of MMP- 2 and MMP-9 substrate degradomes by iTRAQ-TAILS quantitative proteomics. Mol Cell Proteomics 2010, 9:894-911.

119. Starr AE, Bellac CL, Dufour A, Goebeler V, Overall CM: Biochemical characterization and $\mathrm{N}$-terminomics analysis of leukolysin, the membrane-type 6 matrix metalloprotease (MMP25): chemokine and vimentin cleavages enhance cell migration and macrophage phagocytic activities. J Biol Chem 2012, 287:13382-13395.

120. Bolli R, Patel BS, Jeroudi MO, Lai EK, McCay PB: Demonstration of free radical generation in "stunned" myocardium of intact dogs with the use of the spin trap alpha-phenyl N-tert-butyl nitrone. J Clin Invest 1988, 82:476-485.

121. Jacob C, Giles Gl, Giles NM, Sies H: Sulfur and selenium: the role of oxidation state in protein structure and function. Angew Chem Int Ed Engl 2003, 
42:4742-4758

122. Lassègue B, San Martín A, Griendling KK: Biochemistry, physiology, and pathophysiology of NADPH oxidases in the cardiovascular system. Circ Res 2012, 110:1364-1390.

123. Santos CXC, Anilkumar N, Zhang M, Brewer AC, Shah AM: Redox signaling in cardiac myocytes. Free Radic Biol Med 2011, 50:777-793.

124. Burgoyne JR, Mongue-Din H, Eaton P, Shah AM: Redox signaling in cardiac physiology and pathology. Circ Res 2012, 111:1091-1106.

125. Zhang Y, Tocchetti CG, Krieg T, Moens AL: Oxidative and nitrosative stress in the maintenance of myocardial function. Free Radic Biol Med 2012, 53:1531-1540

126. Wang X, Jian C, Zhang X, Huang Z, Xu J, Hou T, Shang W, Ding Y, Zhang W, Ouyang $M$, Wang $Y$, Yang $Z$, Zheng $M$, Cheng $\mathrm{H}$ : Superoxide flashes: elemental events of mitochondrial ROS signaling in the heart. $J \mathrm{Mo} / \mathrm{Cell}$ Cardiol 2012, 52:940-948

127. Tabima DM, Frizzell S, Gladwin MT: Reactive oxygen and nitrogen species in pulmonary hypertension. Free Radic Biol Med 2012, 52:1970-1986.

128. Chalkias A, Xanthos T: Redox-mediated programed death of myocardial cells after cardiac arrest and cardiopulmonary resuscitation. Redox Rep 2012, 17:80-83.

129. Pacher P, Beckman JS, Liaudet L: Nitric oxide and peroxynitrite in health and disease. Physiol Rev 2007, 87:315-424.

130. GeY, Moss RL: Nitroxyl, redox switches, cardiac myofilaments, and heart failure: a prequel to novel therapeutics? Circ Res 2012, 111:954-956

131. Murray Cl, Uhrigshardt H, O'Meally RN, Cole RN, van Eyk JE: Identification and quantification of S-nitrosylation by cysteine reactive tandem mass tag switch assay. Mol Cell Proteomics 2012, 11:M111.013441.

132. Wang H, Qian W-J, Chin MH, Petyuk VA, Barry RC, Liu T, Gritsenko MA, Mottaz HM, Moore RJ, Camp li DG, Khan AH, Smith DJ, Smith RD: Characterization of the mouse brain proteome using global proteomic analysis complemented with cysteinyl-peptide enrichment. J Proteome Res 2006, 5:361-369.

133. Lee J-S, Smith E, Shilatifard A: The language of histone crosstalk. Cell 2010 142:682-685.

134. Mishra S, Ande SR, Salter NW: O-GICNAc modification: why so intimately associated with phosphorylation? Cell Commun Signal 2011, 9:1.

135. GuY, Ande SR, Mishra S: Altered O-GlcNAc modification and phosphorylation of mitochondrial proteins in myoblast cells exposed to high glucose. Arch Biochem Biophys 2011, 505:98-104.
136. Wang Z, Gucek M, Hart GW: Cross-talk between GlcNAcylation and phosphorylation: site-specific phosphorylation dynamics in response to globally elevated O-GIcNAc. Proc Natl Acad Sci USA 2008, 105:13793-13798.

137. Graham ME, Thaysen-Andersen M, Bache N, Craft GE, Larsen MR, Packer NH, Robinson PJ: A novel post-translational modification in nerve terminals: O-linked N-acetylglucosamine phosphorylation. J Proteome Res 2011, 10:2725-2733.

138. Hahne H, Kuster B: Discovery of O-GlcNAc-6-phosphate modified proteins in large-scale phosphoproteomics data. Mol Cell Proteomics 2012, 11:1063-1069.

139. Matic I, Schimmel J, Hendriks IA, van Santen MA, van de Rijke F, van Dam H, Gnad F, Mann M, Vertegaal ACO: Site-specific identification of SUMO-2 targets in cells reveals an inverted SUMOylation motif and a hydrophobic cluster SUMOylation motif. Mol Cell 2010, 39:641-652.

140. Yao Q, Li H, Liu B-Q, Huang X-Y, Guo L: SUMOylation-regulated protein phosphorylation, evidence from quantitative phosphoproteomics analyses. J Biol Chem 2011, 286:27342-27349.

141. Ruderman NB, Xu XJ, Nelson L, Cacicedo JM, Saha AK, Lan F, Ido Y: AMPK and SIRT1: a long-standing partnership? Am J Physiol Endocrinol Metab 2010, 298:E751-E760.

142. Low JKK, Wilkins MR: Protein arginine methylation in Saccharomyces cerevisiae. FEBS J 2012, 279:4423-4443.

143. Chen C, Nott TJ, Jin J, Pawson T: Deciphering arginine methylation: Tudor tells the tale. Nat Rev Mol Cell Biol 2011, 12:629-642.

144. Black JC, Whetstine JR: Tipping the lysine methylation balance in disease. Biopolymers 2013, 99:127-135.

145. Calise J, Powell SR: The ubiquitin proteasome system and myocardial ischemia. Am J Physiol Heart Circ Physiol 2012, 304:H337-H349.

doi:10.1186/gm424

Cite this article as: Liddy KA, et al.: Functional decorations: posttranslational modifications and heart disease delineated by targeted proteomics. Genome Medicine 2013, 5:20. 